[Short Communication]

\section{Geographical host change in the kleptoparasitic spider Argyrodes kumadai associated with distribution of two host species}

\author{
Yuki G. Baba* \& Tadashi Miyashita
}

\section{Laboratory of Biodiversity Science, School of Agriculture and Life Sciences, University of Tokyo, Yayoi 1-1-1, Bunkyo-ku, Tokyo, 113-8657, Japan \\ *Correspondence Email: ybaba@es.a.u-tokyo.ac.jp}

\begin{abstract}
We examined host utilization pattern of the kleptoparasitic spider Argyrodes kumadai along a geographical gradient from central Japan to southwest Islands. Host species changed abruptly between Yakushima Island and Amami-oshima Island: Agelena silvatica (Agelenidae) in northern regions and Cyrtophora moluccensis (Araneidae) in southern regions. This is the first report showing allopatric host change in kleptoparasitic spiders.
\end{abstract}

Key words - Agelena limbata, Agelena silvatica, Cyrtophora moluccensis, host-parasite

Spiders in the genus Argyrodes are well known as kleptoparasites that acquire food by invading web of other spiders. Argyrodes spiders show highly divergent behavioral (especially foraging), morphological and life history traits among species (summarized in Whitehouse et al. 2002). The diversity in these traits appears to have arisen from adaptation to different host spider species because difference in host use could promote trait differentiation of parasites through change in selection pressure. To test this hypothesis, comparison between populations utilizing different hosts seems to be useful. Nevertheless intra-specific variation of local host use has not been reported in the Argyrodes spiders. Here we report an abrupt change in host usage of $A$. kumadai along a geographical gradient.

Argyrodes kumadai uses three-dimensional webs constructed mainly by araneid and agelenid spiders, and relies on prey stealing to acquire food although it sometimes prey on host spider (Tanaka 1984). This species shows a broad range distribution from south-west islands of Okinawa to north-east parts of Honshu in Japan, and uses mainly two phylogenetically unrelated hosts, Agelena silvatica (Agelenidae) and Cyrtophora moluccensis (Araneidae) in Japan (Ohkouji 1969, Tanaka 1984, Chikuni 1989). Agelena silvatica that has been misidentified as Agelena limbata (Zhang et al. 2005) is a temperate species distributed in Japan, Korea and China (Tanikawa 2005). In Japan, this species is found from Kyushu to Hokkaido, but not found in south-west Islands except for Yaeyama Islands (Tanikawa 2005). Cyrtophora moluccensis is distributed from tropics to subtropics including New Guinea, Indonesia, Taiwan, and Japan (Platnick 2005). As most part of Japan belongs to temperate zone except for south-west islands, abundance of $C$. moluccensis is likely to be low in the mainland. Thus we expected that host of A. kumadai changed dramatically between south-west islands of Okinawa and the mainland associated with difference in host distribution.

We investigated host density and host usage of $A$. kumadai in 5 areas from Okinawa Island to the Boso peninsula in June and July 2003 (Fig. 1). The habitat characteristics of $C$. moluccensis and A. silvatica were similar in that they are often found at the forest edge or hedgerow adjacent to arable lands. We selected several typical habitats (from 3 to 7 sites) in each area and established several transects (from 2 to 6) in each habitat. We recorded the number of potential host species and the number of $A$. kumadai in host webs that were found along the transects $(158 \pm 123(\mathrm{~m})$ (mean $\pm \mathrm{SD})$ ).

Host density changed dramatically in the boundary be-

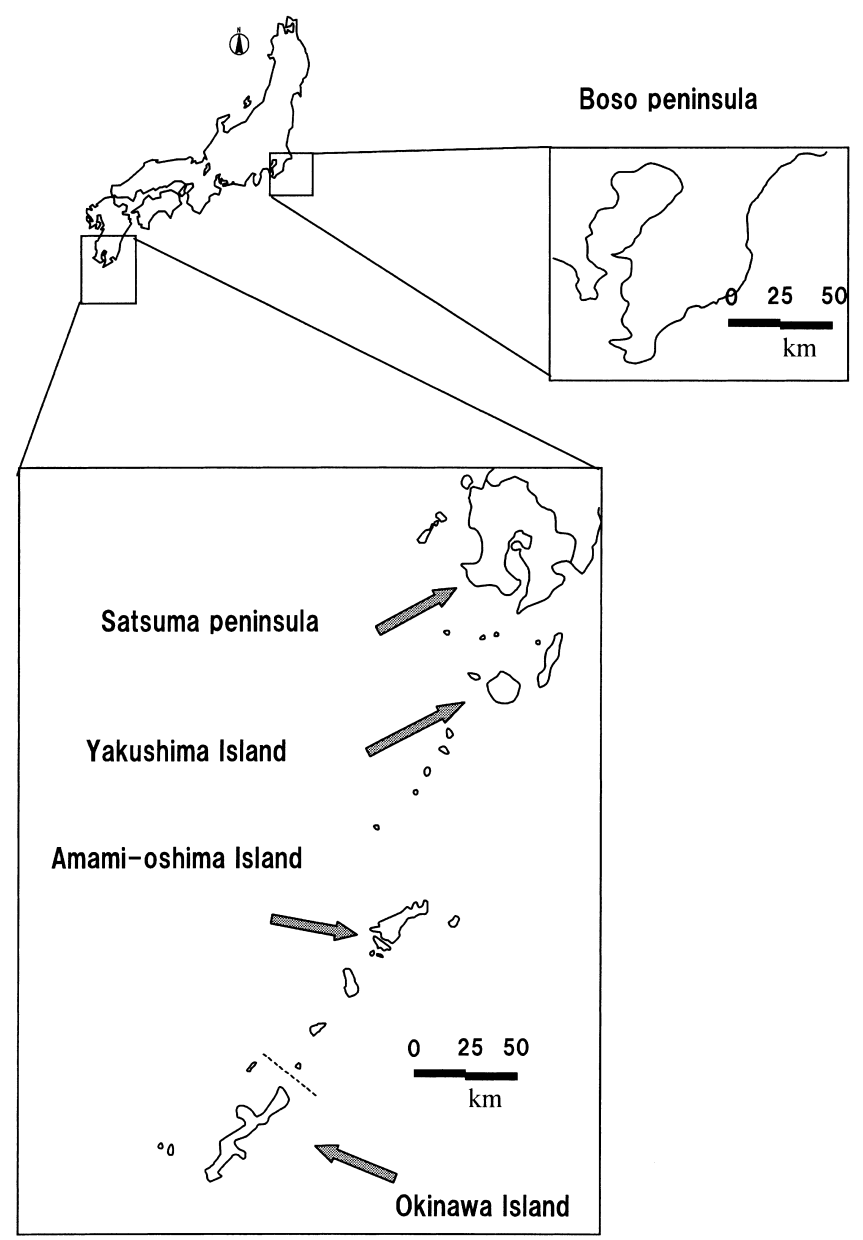

Fig. 1. Map showing the location of 5 study areas in Japan. 
tween Amami-oshima Island and Yakushima Island (Fig. 2a). A. silvatica was abundant in Yakushima Island and northern areas, but not found in Amami-oshima and Okinawa Islands. In contrast, C. moluccensis decreased abruptly between Amami-oshima Island and Yakushima Island, and not found in the Satsuma peninsula and the Boso peninsula. This change in host density reflected the host utilization pattern of $A$. kumadai, which also changed dramatically between the boundary of Yakushima Island and Amami-oshima Island (Fig. 2b). In all areas, no other web spiders were the host of $A$. kumadai. In Yakushima Island, A. kumadai was found only on the web of $A$. silvatica although two host spiders coexisted. This seems to reflect simply the difference in host availability because mean density of $A$. silvatica was 50 times larger than that of $C$. moluccensis.

Vollrath (1984) classified Argyrodes spiders into generalists and specialists. A. kumadai seems to be a specialist to large three-dimensional web weavers. In Japan large threedimensional web weavers are mostly restricted to $A$. silvatica and the genus Cyrtophora spp. Such a narrow host range appears to have led to the regional host change.

a)

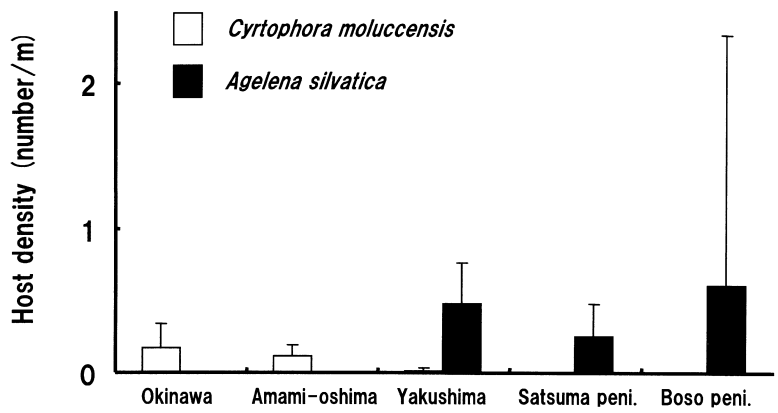

b)

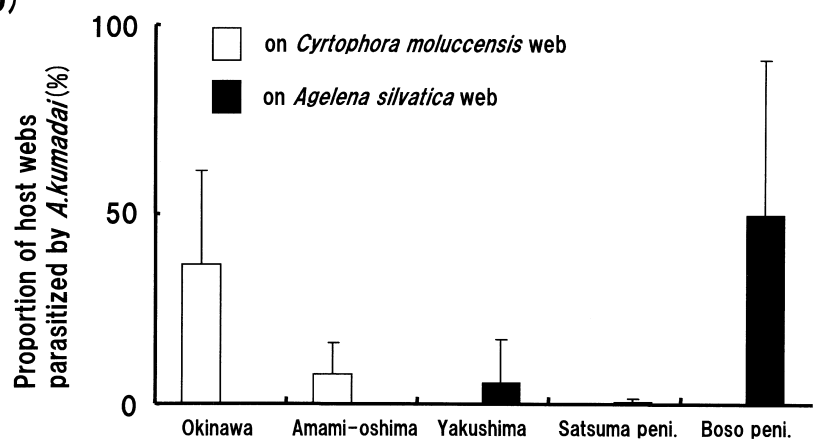

Fig. 2. a) Density of two hosts Cyrtophora moluccensis and Agelena silvatica in 5 areas. b) Proportion of host webs parasitized by Argyrodes kumadai in 5 areas. Bars represent 95\% confidence limits of the mean.
Local host difference is known to cause trait differentiation in parasites between populations (Thompson 1994). In the system of kleptoparasitic spiders and web spiders, host spiders are likely to affect various ecological conditions for Argyrodes spiders including foraging tactics, food availability, and predation risk associated with host web structure and behavior (Whitehouse 1988; Hénaut et al. 2005). Although both $C$. moluccensis and A. silvatica construct three-dimensional webs, detailed structures are quite different. The web of $C$. moluccensis is a dome-shaped web, while the web of A. silvatica is a flat sheet web with a retreat. Moreover, foraging strategy appears to be different between agelenid and araneid spiders (Nentwig 1987). It would be interesting to examine how these differences affect various ecological and behavioral characteristics of $A$. kumadai.

\section{Acknowledgments}

We express great thanks to the staff of Amami Wildlife Conservation Center, Primate Research Institute of Kyoto University, and Experimental forest of Ryukyu University for providing lodging for field survey. We also thank Yuya D. Watari for helping field survey in Amami-oshima Island and Kiyoko Kato for providing information about host habitats in Yakushima Island.

\section{References}

Chikuni, Y. 1989. Pictorial Encyclopedia of Spiders in Japan. Kaiseisha, Tokyo. (In Japanese)

Hénaut, Y., Delme, J., Legal, L. \& Williams, T. 2005. Host selection by a kleptobiotic spider. Naturwissenschaften, 92: 95-99.

Nentwig, W. 1987. The prey of spiders. pp 249-263. In: Nentwig W. (ed.) Ecophysiology of Spiders. Springer-Verlag, Berlin.

Ohkouji, T. 1969. Argyrodes spiders. Kishidaia, 9: 1-2. (In Japanese)

Platnick, N. I. 2005. The World Spider Catalog, version 5.0. Am. Mus. Nat. Hist., Online from:

http://research.Amnh.org/entomology/spiders/catalog

Tanaka, K. 1984. Rate of predation by a kleptoparasitic spider, Argyrodes fissifrons, upon a large host spider, Agelena limbata. J. Arachnol., 12: 363-367.

Tanikawa, A. 2005. Japanese spiders of the genus Agelena (Araneae: Agelenidae). Acta Arachnologica, 54: 23-30.

Thompson, J. N. 1994. The Coevolutionary Process. The University of Chicago Press.

Vollrath, F. 1984. Kleptobiotic interactions in invertebrates. pp. 6194. In: Barnard, C. J. (ed.) Producers and Scroungers: Strategies of Exploitation and Parasitism. Grom Helm, London \& Sydney.

Whitehouse, M. E. A. 1988. Factors influencing specificity and choice of host in Argyrodes antipodiana (Theridiidae: Araneae). J. Arachnol., 16: 349-355.

Whitehouse, M., Agnarsson, I., Miyashita, T., Smith, D., Cangialosi, K., Masumoto, T., Li, D. \& Hénaut, Y. 2002. Argyrodes: phylogeny, sociality and interspecifc interactions - a report on the Argyrodes symposium, Badplaas 2001. J. Arachnol., 30: 238-245.

Zhang, Z. S., Zhu, M. S. \& Song, D. X. 2005. On Agelena labyrinthica (Clerck, 1757) and some allied species, with descriptions of two new species of the genus Agelena from China (Araneae: Agelenidae). Zootaxa, 1021: 45-63.

Received November 4, 2005 / Accepted November 18, 2005 